\title{
Feitiçaria e esfera pública: Estado e cultura no pós-guerra angolano
}

\author{
Luena Nunes Pereira ${ }^{1}$
}

Resumo: Este texto analisa diferentes formas de percepção sobre a feitiçaria assumidas em dois Estados africanos através do debate público sobre acusações de feitiçaria em Angola e África do Sul. A análise parte da descrição dos processos de produção e apropriação de dois relatórios antropológicos realizados nestes países. Estes relatórios procuraram explicar a "reemergência" de acusações em seus contextos nacionais e sugerir políticas públicas para evitar e controlar ataques a supostos feiticeiros. Comparo o "Relatório Ralushai", vindo a público na África do Sul em 1996, com o relatório produzido em Angola entre 2001 e 2003, mas não publicado, que chamarei de "Relatório Friedman-Nsenga". As formas de tratamento que cada relatório recebeu permitem perceber o lugar do debate público sobre feitiçaria nos dois países revelando as tensões entre perspectivas modernizantes e as de defesa do direito tradicional e da diversidade cultural.

Palavras chave: feitiçaria; Angola; África do Sul; pluralismo jurídico.

Abstract: This article analyses different forms of perception of witchcraft in two African countries by focusing the public debate in Angola and South Africa about witchcraft accusations. The analysis takes as its starting point the processes of production and appropriation of two anthropological reports made in these countries. These reports tried to explain the "re-emerging" of accusations in each national context and to suggest public policies to avoid and control attacks against supposed sorcerers. We compare the "Ralushai Report", published in South Africa in 1996, with the unpublished report produced in Angola between 2001 and 2003, which I shall call "Friedman-Nsenga Report". The treatment that each report has received shows the place of public debate about witchcraft in these two countries, revealing tensions between modernizing

1 Profa. Adjunta de Antropologia Social na Universidade Federal Rural do Rio de Janeiro. Email: luenapereira@yahoo.com.br. 
perspectives and the defense of customary law and cultural diversity.

Keywords: Witchcraft; Angola; South Africa; Juridical pluralism.

\section{Introdução}

A chamada "ressurgência" dos fenômenos relacionados à feitiçaria ${ }^{2}$ envolvendo acusações e ataques a supostos feiticeiros em diversos países africanos tem posto por terra a idéia de que a feitiçaria seja um resíduo de crenças persistentes em populações pouco assimiladas à vida moderna. Pelo contrário, a feitiçaria tem se revelado um fenômeno relacionado ao espaço urbano e à economia de mercado, servindo de linguagem a disputas políticas e eleitorais e veiculada inclusive entre população escolarizada e cristianizada (Geschiere 1997, Moore e Sanders 2001). Alguns dos autores responsáveis pela renovação dos estudos de feitiçaria nos últimos 15 anos têm se detido na análise da relação entre feitiçaria e economia, através da idéia de feitiçaria como "economia oculta" (Comaroff e Comaroff 1999), onde o consumo de vidas humanas se dá num sistema de reciprocidade espúria, no qual se assiste a uma profunda disparidade na troca e atribuição de valor.

Em continuidade com análises clássicas, segundo as quais períodos de abrupta transformação social são propícias para o recrudescimento de acusações de feitiçaria (Douglas 1970), autores contemporâneos vêm buscando relações entre movimentos de limpeza de feiticeiros (witch cleansing) e processos de democratização e mudança social acelerada (Ashforth 1998, Niehaus 1998). Esta abordagem aponta para a relação entre feitiçaria e emergência do estado póscolonial, inseparável das novas formas de capitalismo e exclusão política e social. Outros autores também têm destacado a feitiçaria como um idioma eficaz na expressão de concepções populares sobre o Estado, através da definição de Estado (e feitiçaria) como poder oculto e como apropriação ilegítima da força vital (Rowlands e Warnier 1988, Ciekawy 1998, Bayart 1993, Schatzberg 2000). Assim, feitiçaria é considerada tanto uma linguagem crítica para falar do exercício do poder nos novos estados africanos, marcados por sistemas autoritários e fechados, semelhante à idéia de “conluio de bruxas" em encontros secretos (Geschiére 1997), mas também como ação que busca o

2 Utilizo o termo feitiçaria por ser o termo utilizado correntemente em Angola (os termos locais são também utilizados, permutados com o termo em português feitiçaria). Em Luanda, especialmente entre os Bakongo não percebi nenhuma distinção importante entre feitiçaria e bruxaria, nem a utilização de termos distintos para ação mágica consciente e inconsciente, distinção de meios técnicos e poder inato, etc.. 
controle político - e autonomia simbólica - de determinados grupos em períodos de incerteza social.

Angola e África do Sul assistiram, em períodos recentes de transição política, a emergência de ataques a "feiticeiros". Guardadas especificidades históricas e inseridas em contextos distintos, ambos países passaram por processos, respectivamente, de pacificação interna (fim da guerra civil angolana em 2002) e democratização (fim do apartheid e transição para regime de maioria na África do Sul, nos anos 1990). Uma descrição mais detalhada sobre o caso angolano de acusações a crianças e adolescentes está no texto de Pereira (2008), a partir de trabalho de campo realizado entre 2006 e 2007, e será retomado em alguns aspectos neste texto. O caso sul-africano será referido com base em bibliografia secundária (Niehaus 2001, Ashfort 1998, Harnischfeger 2001) como um contraponto para pensar a situação angolana.

O recrudescimento dos casos de acusações de feitiçaria num contexto social e político considerado "moderno" vem desafiando diversos estados africanos que, herdeiros de sistemas jurídicos construídos no período colonial, vêm tendo dificuldades de lidar com o fenômeno de forma consistente, no sentido de dar respostas consideradas legítimas ou eficazes no controle de acusações e crimes perpetrados contra supostos feiticeiros.

As legislações de origem colonial sobre feitiçaria buscavam explicitamente coibir o fenômeno reprimindo as acusações de feitiçaria e seus agentes (feiticeiros, curandeiros) e métodos de detecção de feiticeiros (ordálio e outros rituais de adivinhação). O fracasso destas legislações deu espaço para interpretações sobre a "persistência" da feitiçaria e sua existência como uma realidade "irredutível" africana, seja retomando concepções essencialistas e racistas, seja afirmando positivamente a feitiçaria uma especificidade cultural africana. Mesmo concepções modernizantes, que traduzem o recrudescimento da feitiçaria pelo aspecto do subdesenvolvimento, da pobreza e do aumento da desigualdade, reconhecem a necessidade de novos instrumentos jurídicos e outras políticas específicas para a abordagem do fenômeno.

Alguns governos africanos têm problematizado a não universalização efetiva dos sistemas jurídicos herdados do colonialismo nos espaços nacionais e a sua distância e não legitimidade frente a maioria da população. Assim, têm debatido a necessidade de criar novas leis ou de "pluralizar o regime jurídico" que supere o sistema implementado durante o regime colonial, de perspectiva modernizante. Trata-se entre outras medidas, de flexibilizar e 
descentralizar o sistema jurídico reconhecendo formalmente algum lugar para o chamado "sistema costumeiro" e/ou de mecanismos locais de regulação de conflitos através de um papel renovado das chamadas "autoridades tradicionais". O debate passa pela idéia de conferir maior legitimidade aos processos jurídicos aproximando-os das formas populares de resolução de conflito e de reconhecer especificidades "africanas" no que tange a compreensão das causas de determinados conflitos e formas de conciliação. A possibilidade de mudança da legislação e introdução de novas políticas de regulação de conflitos abre espaço para a ideia de reconhecimento da feitiçaria como fenômeno "tipicamente africano", o que significa exigir soluções também "africanas"”.

Procuro fazer uma breve análise sobre as diferentes formas de percepção e reconhecimento destas "realidades africanas" e das posições assumidas por dois Estados pós-coloniais frente o fenômeno da feitiçaria, analisando o debate sobre acusações de feitiçaria em Angola e África do Sul. Esta análise será feita a partir da descrição de dois processos distintos de produção e apropriação de relatórios antropológicos produzidos nos dois países que procuram explicar a "reemergência" de acusações de feitiçaria em seus contextos nacionais e sugerir políticas públicas ou legislações específicas para conter, evitar e controlar ataques a "feiticeiros". Comparo o chamado "Relatório Ralushai", vindo a público na África do Sul em 1996, com o relatório produzido com financiamento do governo angolano e internacional entre os anos de 2001 e 2003, mas não publicado, que chamarei aqui de "Relatório Friedman-Nsenga".

As formas de tratamento que um e outro relatório receberam pelo governo e pelos meios de comunicação e acadêmicos revelam o lugar do debate público sobre feitiçaria nos dois países e o pensamento de determinados grupos e instituções do Estado sobre as tensões entre perspectivas modernizantes e de defesa do "direito tradicional".

Para compreender as diferentes posições assumidas nestes Estados frente ao fenômeno da feitiçaria será necessário fazer algumas comparações sobre os mecanismos pelos quais o estado sulafricano no período colonial e do apartheid tratou legal e praticamente das questões concernentes à feitiçaria como forma de iluminar e organizar o que sabemos sobre os procedimentos portugueses na Angola colonial. Os mecanismos pós-coloniais pelos quais o Estado angolano vem lidando com

3 A temática da mediação de conflitos associados a acusação de feitiçaria está intimamente relacionada com o debate sobre autoridades tradicionais e pluralismo jurídico. As pesquisas sobre estes dois temas têm sido bem mais aprofundadas em Moçambique (Granjo 2011, Meneses 2009, Florêncio 2008) do que em Angola. Ver Florêncio 2011 para o caso da região central de Angola. 
questões concernentes à feitiçaria em Angola estão de várias formas relacionados com o período colonial, mas também condicionados pela guerra civil que marcou todo o período pósindependência até 2002. Possuímos, entretanto, poucas referências sobre o tratamento dado pelo Estado angolano ao fenômeno da feitiçaria até a recente emergência das acusações contra crianças. Todavia estas reflexões servirão para refletirmos sobre aspectos do estado pós-colonial angolano e formas de resolução de conflito no contexto da guerra civil e pós-guerra civil.

\section{Acusações de feitiçaria em Angola e na África do Sul}

\section{Angola e o Relatório Friedman-Nsenga}

Acusações de feitiçaria a crianças e adolescentes têm emergido na África Central, especialmente na República Democrática do Congo (RDC) nos últimos 15 anos $^{4}$. Em Angola este fenômeno tem sido registrado desde os anos 2000 com maior prevalência entre o grupo étnico Bakongo $^{5}$, tanto nas províncias do norte de Angola (Zaire e Uíge), de prevalência de população Bakongo, como em Luanda entre a comunidade Bakongo ali residente.

As acusações têm sido descritas, tanto por mais velhos e líderes das igrejas mais antigas como pelo governo e ONGs, como resultado da desestruturação familiar ocasionada pela guerra civil, no caso de Angola, e pela alta instabilidade política e crise econômica e social na RDC. As acusações às crianças em geral acontecem dentro das famílias ou entre vizinhos. Elas são acusadas de manipularem forças advindas do mundo noturno ocasionando infortúnios dentro das famílias como doenças, mortes, abortos e fracasso econômico. As crianças acusadas situam-se, na maior parte das vezes, na faixa etária entre 8 a 13 anos, embora não seja incomum a acusação a crianças muito pequenas, inclusive bebês.

4 Acusações de feitiçaria a crianças têm sido observadas também em países da África Ocidental e Central como Nigéria, Gana e Camarões (UNICEF, 2010)

5 A designação "grupo étnico Bakongo" não é unívoca e é usada a partir de alguns critérios que se superpõem. Um critério refere-se à população de língua kikongo (ainda que parte da população residente ou nascida em Luanda não fale a língua materna). Outro é a auto-atribuição de indivíduos e populações oriundas (ou delas descendentes) da região norte de Angola (atuais províncias do Zaire e Uíge). Estas populações conferem grande importância ao território referido ao antigo reino do Congo. Apesar da necessária relativização do uso do termo etnia ou grupo étnico devido à consciência dos processos de invenção e emergência étnica, entendemos que a dimensão histórica e processual dos grupos étnicos são seus elementos constitutivos e não desmobilizam o uso do termo. A designação "grupo Bakongo" é utilizada com a atenção aos processos ambíguos e maleáveis de reconhecimento, de autoatribuição e de atribuição. O termo "de origem bakongo" faz referência aos bakongo nascidos e/ou residentes em Luanda que não fazem uso contínuo do kikongo. 
Comportamentos considerados desviantes de crianças e adolescentes, como agressividade, indolência, inquietude e dispersão podem justificar a acusação. Sintomas como fome excessiva, enurese noturna, sono agitado ou excessivo e doenças como epilepsia e sonambulismo também são associados a "crianças feiticeiras".

A grande maioria das crianças acusadas são crianças órfãs de um dos pais ou ambos, sendo acolhidas por parentes como tios ou avós, ou vivem com padrastos ou madrastas que muito frequentemente são os responsáveis pelas acusações. Esta caracterização familiar indica, segundo relatórios de ONGs de proteção à criança (CCF 2003, Molina 2005, Stobart 2006), a tensão e sobrecarga que acometem as famílias obrigadas a acolherem crianças que, pela guerra, deslocamentos, migrações ou pela emergência do HIV-SIDA, perdem seus parentes diretos. Muitas vezes as crianças são acusadas de matarem seus próprios pais falecidos em decorrência da SIDA.

De Boeck (2000, 2004, 2005) se dedicou à análise deste fenômeno no Congo (RDC), a partir da perspectiva das crianças em situação de rua. O autor ressaltou o novo papel econômico das crianças e a alteração da balança de poder entre gerações a partir da participação de crianças na economia informal e na exploração de diamantes. Em Angola verifica-se também a intensa participação de crianças na economia informal, principalmente em Luanda.

Frequentemente as crianças são acusadas a partir da consulta de algum familiar a um pastor de igreja pentecostal ou de igreja africana ${ }^{6}$ ou um curandeiro tradicional. O pastor detecta a causa dos infortúnios familiares no poder maligno de determinada criança. A partir daí, estas crianças são passíveis de sofrerem maus tratos pelos parentes. Muitas são expulsas ou fogem de casa. Estas mesmas igrejas prometem "tratamento espiritual" capaz de curar as crianças acometidas de feitiçaria. As igrejas e seus pastores são acusados de tratamento indigno, submetendo as crianças a reclusão, jejuns e medicamentos agressivos.

Em Angola, acusações de feitiçaria contra crianças e adolescentes se tornaram uma preocupação do governo com centenas de casos reportados ${ }^{7}$. Em 2001 foi lançado um edital

6 A distinção entre igrejas pentecostais e africanas (também chamadas proféticas ou mpeve (y)a longo, termo kikongo para Espírito Santo) atende a um critério de origem destas igrejas. Igreja profética ou africana seria uma designação genérica para igrejas de origem africana e pentecostal seriam aquelas vindas da Europa ou das Américas. Quanto às práticas adotadas, tais como rituais de cura, eventos de glossolalia e exorcismo, encontramos entre elas mais semelhanças que distinções. Refiro-me ao termo genérico pentecostais para me referir aos dois tipos.

7 Os casos de crianças acusadas vieram à tona através do recrudescimento do fenômeno de crianças de rua. Somente em M'Banza Congo, capital da província do Zaire, o governo provincial afirmou que em 2000 haviam mais de 400 crianças em situação de rua, expulsas de casa devido a acusações de feitiçaria. No caso de Luanda não há dados disponíveis. Os centros de acolhida de crianças tendem a não identificar crianças acusadas para prevenir situações 
encomendado pelo INAC - Instituto Nacional da Criança, do governo angolano - pela UNICEF e pela ONG internacional de proteção da criança, Save the Children, seção Noruega (SC-N) com a intenção de fazer uma primeira prospecção do fenômeno, fornecer dados, explicações especialmente de caráter antropológico - para o fenômeno e propor medidas e políticas de prevenção e solução da crise.

A coordenação da pesquisa (designada "consultora internacional") coube à antropóloga sueca Kajsa Ekholm Friedman. Como “consultor nacional”, tomou parte o sociólogo angolano Biluka Nsakala N'senga, também Secretário Provincial da Cultura da província do Zaire. Foi realizada pesquisa de campo durante os anos de 2001 e 2002 com uma equipe de pesquisadores angolanos falantes de kikongo. Circulou por ONGs de proteção à criança um "relatório preliminar", concluído em 2002: "Estudo sobre as crianças em situação de risco nas províncias de Zaire, Uíge e Luanda. Relatório Preliminar”. Funcionários da ONG Christian Children Fund, organização que apoiou meu trabalho de campo, me permitiram o acesso a este relatório.

O relatório é rico em dados de campo, com muitas transcrições de entrevistas com as crianças acusadas, autoridades tradicionais e funcionários de centros de acolhida a crianças de rua (estatais e da igreja católica). Foi detectado que boa parte das crianças que estavam na rua foram expulsas ou fugiram de casa devido as acusações. O relatório procurou estabelecer relações para com o universo de crenças e das práticas religiosas bakongo, centradas na idéia da reciprocidade entre os dois mundos. Nesse sentido, aponta para a transformação do lugar da criança neste universo, que passa a ser vista como um elemento ameaçador e desestruturador da família, e não mais percebida como a continuidade da linhagem. A acusação às crianças, que indica uma inversão dos papéis - posto que tradicionalmente as acusações eram direcionadas aos mais velhos sinalizaria assim a desestruturação da família e da linhagem.

Outra causa das acusações de feitiçaria na atualidade estaria, ainda segundo o relatório, no vazio de poder verificado entre os Bakongo com a destituição do poder tradicional local pela concentração política do Estado angolano que, por sua vez, não se faria presente no país, na região norte em particular. Consta também a revisão, ainda que de forma muito breve, de alguns dos estudos recentes sobre feitiçaria em África e a busca de interpretar os depoimentos de crianças que afirmam serem feiticeiras. Também descreve e analisa algumas práticas de minimização e resolução das acusações de feitiçaria a crianças, especialmente empreendidas por ONGs e instituições da 
igreja católica.

O relatório põe em relação as acusações de feitiçaria a fatores como pobreza e desarticulação social, devido à guerra e ao peso econômico que a família extensa carregaria ao abrigar mais crianças órfãs ou deslocadas de guerra do que ela seria capaz de suportar. Outro aspecto residiria na "desestruturação da sociedade kongo" e do seu sistema de parentesco, situação agravada pela presença das "seitas" pentecostais, especialmente as de origem congolesa, que seriam as principais disseminadoras das acusações de feitiçaria a crianças. A falta de autonomia política das instituições locais de regulação - conselho de anciãos, autoridades tradicionais - e a pouca presença das instituições do Estado naquelas regiões ou nas periferias de Luanda foi apontada como fator importante que dificultaria uma solução duradoura ao problema.

O relatório é bastante orientado pelos discursos dos mais-velhos, especialmente as "autoridades tradicionais" atuantes nas províncias do norte do país. Há longas transcrições com as explicações destas autoridades sobre como se identificava um feiticeiro e como ele era tratado julgado, morto ou expulso. É importante ressaltar que estes mais velhos fazem referência a existência de crianças feiticeiras em tempos anteriores, mas que, entretanto, não eram expulsas de suas casas, mas sim tratadas pelos curandeiros. A acusação às crianças não seria um fenômeno totalmente novo, mas sim a disseminação sistemática das acusações, a expulsão de crianças do meio

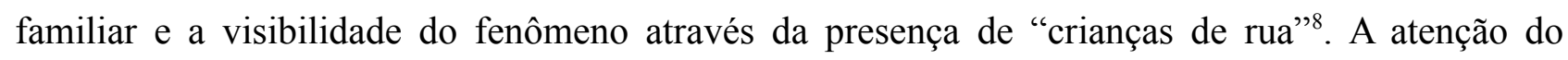
relatório centra-se na retirada pelo Estado - colonial e angolano - do poder das autoridades tradicionais de resolverem internamente os problemas de feitiçaria.

O mecanismo do processo de desintegração em curso tem muito a ver com a relação irregular entre a sociedade Kongo e o setor governamental. Os Bakongo vivem numa situação onde perderam muitas das suas instituições vitais para um sistema estatal mais bem sucedido e poderoso. O sistema judicial existente, por exemplo, é estrangeiro. Este impede-os de lidarem com o problema da feitiçaria na arena pública. (...) É nossa convição que remédios eficazes para os problemas dos Bakongo, incluindo a feitiçaria, só poderão ser alcançados com a descentralização de algumas funções do estado e um programa de assistência social mais desenvolvido. (Friedman e N'Senga 2002, 43)

\footnotetext{
8 A atribuição de feitiçaria a crianças no relato dos mais velhos (que consta no Relatório Preliminar, mas que também escutei nas conversas com mais velhos em Mbanza Congo) estaria também relacionada a transmissão do poder entre tio materno e sobrinho como forma de proteção à linhagem. O uso do termo feitiçaria para designar esta transmissão de poder oculto entre gerações - que não seria um poder maligno, mas um poder oculto benigno, para fins de proteção demonstra a formulação local do termo feitiçaria que se mantém repleto de ambiguidades.
} 
Esse é o ponto crucial - a necessidade de abordar o problema da feitiçaria a partir do ponto de vista dos próprios Bakongo e basear a ajuda oferecida na sugestão de reforço da instituição de autoridades tradicionais e de delegação da autoridade legal ao tribunal costumeiro quando se trata de casos de feitiçaria. Nós concordamos inteiramente com a afirmação da [...] quando diz que a experiência enraizada dos Bakongo e o conhecimento de feitiçaria devem ser respeitados, e é acima de tudo inaceitável que estrangeiros de outra cultura sejam permitidos decidir sobre o que existe e o que não existe. Os projetos falham porque estão muito distanciados das realidades locais. Os doadores têm a sua própria cultura e assim sendo, os seus resultados 'raramente refletem a nossa concreta realidade'. 'Todos os projetos deveriam tomar em consideração essa realidade, isto é, a cultura e sociedade do nosso país'. (Idem, 88)

Entre as principais recomendações do relatório estão, portanto, o "reforço da instituição das 'autoridades tradicionais"” e a "descentralização e delegação da autoridade legal ao tribunal de direito costumeiro quando se trata de casos de feitiçaria" (pg. 73). Isto significa delegar o poder de julgar aos chefes e autoridades tradicionais, além de medidas de caráter sócio-econômico, já que a pobreza seria o fator fundamental apontado como explicação para o recrudescimento das acusações.

A suspeição sobre as igrejas pentecostais ou espirituais são outra tônica do relatório. Os autores ecoam as críticas dos mais velhos às "seitas" e a seus objetivos econômicos, relacionando sua disseminação ao período pós independência. Os autores do relatório também não fazem diferenciação entre as atuações de pastores pentecostais e curandeiros tradicionais e criticam o fato de ambos se auto-atribuírem poderes divinos não passíveis de "contestação racional". Já as autoridades tradicionais são avaliadas de forma diferente dos pastores das igrejas pois, segundo o relatório, estes estariam baseadas em autoridade legítima, sujeitas ao debate público, e suas deliberações seriam voltadas para o "bem comum".

Este relatório não chegou a ser publicado pelas instituições que o encomendaram. Em 2006, outro relatório, “O Impacto das Acusações de Feitiçaria Contra Crianças em Angola: uma análise na perspectiva da proteção dos direitos humanos" foi produzido pelo INAC com a colaboração da UNICEF e publicado em 2006 (Peres e Benge 2006). Entretanto, este outro relatório apresentou poucos elementos para a compreensão do fenômeno. Sem explicações de ordem sócio-econômica ou antropológica para as acusações, é explicitamente voltado para fornecer argumentos de ordem legal e jurídica (a partir das leis angolanas de proteção a criança e cartas internacionais dos direitos da criança) para a abordagem da agressão às crianças. Ainda assim, se valeu do material de campo 
apresentado nas versões (não publicadas) do relatório Friedman-Nsenga, citando extensamente os dados de terreno ali contidos. Todavia não fez quaisquer referências às suas conclusões e recomendações.

Nas instituições ligadas à proteção da infância em Luanda, circularam rumores, informações e versões sobre o que teria impedido a publicação do primeiro relatório e favorecido a produção e publicação do segundo. Durante meu trabalho de campo, nas entrevistas e conversas informais conduzidas com funcionários destas organizações, me foi relatado que a pesquisa empreendida por Friedman teria enfrentado vários problemas. O primeiro foi o desentendimento entre a autora e os pesquisadores angolanos, que teriam afirmado acreditarem na feitiçaria e produzido dados em desacordo com o questionário proposto, como relatórios parciais tendentes a concordar com a existência de crianças feiticeiras, além de opinativos quanto à melhor forma de curar as crianças acusadas. Estes desentendimentos teriam ocasionarado a demissão da equipe (ou, em outras versões, a recusa da equipe em continuar a pesquisa) e o retorno de Friedman à Suécia, de onde produziu a segunda versão do relatório em colaboração exclusiva com Biluka N'senga, que refez parte da pesquisa de terreno em Angola.

Algumas interpretações enfatizaram conflitos entre uma visão "externa" e "interna" do problema, não só opondo colaboradores nacionais e consultora internacional como também questionamentos por parte das instituições do governo sobre a excessiva autoridade de estrangeiros com pouco conhecimento em "assuntos internos".

Um religioso ligado ao Centro Arnaldo Janssen, a principal instituição da igreja católica de acolhida a meninos de rua em Luanda, apontou a "visão estreita" das instituições do governo, excessivamente centradas na visão do conflito a partir da proteção dos direitos da criança. Para ele, esta perspectiva toma a criança como um indivíduo desligado de um sistema mais amplo, que envolve a família, a linhagem, seu entorno comunitário e ambiente cultural. Segundo este religioso, a abordagem do governo, ao focar apenas na proteção da criança e na agressão de um ponto de vista apenas jurídico, criminalizaria a família agressora, perdendo de vista a melhor solução para o problema que seria a reconciliação familiar, tornada impossível se a família é criminalizada por agressão e se amedronta diante das leis e do governo 9 .

9 O Centro Arnaldo Janssen se tornou referência para o caso de crianças acusadas de feitiçaria por propor a tarefa de reintegração da criança acusada na família a partir da organização de reuniões familiares, nas quais as famílias das crianças são chamadas a exporem sua visão do problema e propor soluções. As famílias por vezes propõem "tratamentos" para a "cura" da criança acusada que incluem curas espirituais em igrejas ou com curandeiros, cujos rituais são acompanhados pelos funcionários do Centro para não redundarem em maus tratos. 
Por outro lado, uma importante dirigente do INAC declarou que o relatório antropológico não tinha sido aprovado por este afirmar que as crianças eram de fato feiticeiras. Segundo ela, a abordagem do relatório, que procurou levar em conta concepções locais de causalidade, não poderia ser aceito pelo governo, posto que a feitiçaria seria um "erro", "o governo não pode aceitar" a concepção de que crianças pudessem ser feiticeiras, e a crença na feitiçaria deveria ser desencorajada.

As divergências nas interpretações, explicações e mesmo acusações sobre a não publicação do relatório estão diretamente relacionadas às posições distintas ocupadas por cada um destes agentes (setores do governo, ONGs nacionais, ONGs internacionais, igreja católica, consultores estrangeiros) no campo da produção do fenônemo da criança acusada de feitiçaria. As críticas da instituição católica ao governo se inserem nas disputas entre as diferentes formas de abordar o problema das crianças acusadas, uma enfatizando os direitos da criança de um ponto de vista jurídico e estatal e outra, apontando para a reintegração na família a partir de seus pressupostos culturais (Pereira,2008). Já a ênfase numa visão "interna", seja ela nacional ou local, sobre a questão da criança acusada que procura desqualificar uma visão "estrangeira" do problema, aparece de forma mais ambivalente. A recusa da publicação do relatório por parte do governo (INAC) aparentemente deslegitima a posição de uma especialista "estrangeira" através da acusação de crença ou apoio a crença na feitiçaria. Entretanto o relatório publicado é fruto de uma parceria entre uma institição nacional (INAC) e uma internacional (UNICEF) que prima pela visão modernizante, ao legitimar uma narrativa unificadora e universalista sobre feitiçaria. Esta narrativa exclui tanto percepções "tradicionais" baseadas na crença da feitiçaria (expressas pelos pesquisadores angolanos bakongo) ou as recomendações quanto necessidade de tomar em consideração a "perspectiva local" das autoridades tradicionais. O que aparece como uma posição naciocentrada reflete dissensões internas (entre posições locais e estatais) associadas às contradições das recomendações de organismos internacionais. Estas tentam combinar de forma pouco congruente e pouco clara o respeito pelos direitos humanos à atenção a culturas e poderes locais (ver por exemplo as recomendações do relatório da Unicef 2010).

Cabe ainda uma observação sobre a omissão dos nomes envolvidos nesta polêmica. Esta foi uma opção deliberada na escrita deste texto, na medida em que boa parte das informações obtidas na pesquisa de campo se deram num contexto muito sensível de acusações e contra-acusações entre pessoas e instituições. O rumor foi a forma central de produção e gestão dos conflitos que 
emergiram no processo da produção e da (não) publicação do relatório antropológico. Sei que ao omitir nomes - que entretanto não são difíceis de serem identificados internamente ao contexto das ONGs e organismos governamentais de proteção à criança em Angola - corro o risco de reproduzir a mesma lógica de produção de rumores para a circulação e o controle de informação. Lógica esta que, aliás, guarda muitas semelhanças com a lógica da feitiçaria, no sentido da canalização de ressentimentos e produção de bodes expiatórios a partir da desconfiança e da tentativa de produzir o controle num contexto de incertezas (Stewart e Strathern, 2004). Todavia este risco é menos danoso do que acirrar mais as animosidades ao apontar diretamente pessoas que me forneceram informações baseadas na confiança e no sigilo.

\section{África do Sul e o Relatório Ralushai}

Num período anterior aos acontecimentos de Angola, a África do Sul assistiu, entre os anos 1980 e 1990, uma explosão de ataques, linchamentos e assassinatos de supostos feiticeiros, levados a cabo por populações, principalmente jovens e adolescentes, a revelia do Estado. Foram reportados quase 400 casos de assassinatos relacionados à acusação de feitiçaria entre 1985 e 1995 (Niehaus 2001).

Este fenômeno foi detectado principalmente na Northern Province, num período de transição do regime do apartheid para a democratização. Estavam em desenvolvimento conversações e acordos entre o governo do apartheid (comandado pelo Partido Nacional) com lideranças ligadas ao ANC/African National Congress, principal organização política africana, ilegal desde os anos 1960. Nelson Mandela fora solto no mesmo ano de legalização do ANC, 1990. Em 1993 terminou legalmente o regime do apartheid e em 1994 eleições foram realizadas, dando início a um inédito regime de maioria com o governo do ANC.

Niehaus (2001) atribui a emergência da ansiedade relacionada à feitiçaria neste contexto, entre vários fatores, ao clima de expectativa e incerteza reinante durante este período na qual a instabilidade e certo vazio político na transição de poder fez emergir jovens lideranças insatisfeitas com a ocupação dos mais velhos no sistema de poder pós apartheid. Durante o período mais duro de ilegalidade do ANC, aos mais jovens foram incumbidas as ações radicais de guerrilha urbana, reagindo às violentas políticas repressivas do apartheid e produzindo novos fatos políticos e midiáticos de resistência popular. Com a soltura das lideranças políticas mais velhas, o retorno de 
exilados às negociações e a iminente tomada de poder pelos quadros organizados do ANC, o partido teria passado a prescindir das ações juvenis, que teriam assim se ressentido da perda de espaço político. As ações populares de limpeza de feiticeiros (witch cleansing), voltadas principalmente contra pessoas idosas, mais pobres e fragilizadas, trariam em seu bojo um caráter de moralização e espera messiânica, de reordenamento do social, ao mesmo tempo que sua inversão do ponto de vista da retomada da ação repressiva pelos jovens contra os mais velhos.

Em 1995, na esteira da produção de novos mecanismos políticos e jurídicos de superação do apartheid e de criação de uma "nova" sociedade sul-africana foi criada a "Comission of Inquiry into Witchcraft Violence and Ritual Murders in the Northern Province", mais conhecida como “Comissão Ralushai”, liderada pelo antropólogo que dá nome à comissão, Prof. Ralushai. Também compunham a comissão um professor de direito, um pastor (também magistrado), um advogado, um chefe "tradicional", o presidente do conselho sul africano de curandeiros tradicionais, um teólogo, um militar e um político. O relatório foi publicado em 1996 e foi alvo de um intenso debate na medida em que, pela primeira vez, se propôs explicitamente uma nova forma do Estado sul-africano reconhecer e encarar a "realidade" da feitiçaria e propor mecanismos jurídicos para a sua regulação.

O Relatório Ralushai atribuiu o crescimento da perseguição popular aos feiticeiros à "lei dos brancos", ou seja, ao "Witchcraft Supression Act". Esta lei, de 1957, reproduziu as leis britânicas da virada do século XX que tornava crime a acusação de qualquer pessoa como feiticeiro. Entendendo a feitiçaria como uma superstição diabólica e sem fundamento, a lei pretendia suprimir o circuito de acusações e violência propagado pela feitiçaria através da repressão aos acusadores, supondo que o desenvolvimento da civilização ocidental, através da cristianização e da educação, se encarregaria de dirimir as crenças mais arraigadas que sustentam as acusações de feitiçaria. A feitiçaria era entendida do ponto de vista colonial não como um crime, mas como uma superstição que levava aos crimes propriamente ditos, de acusação, perseguição e assassinato de supostos feiticeiros. Criminalizando os curandeiros que identificavam feiticeiros, a proibição da feitiçaria criminalizava, por extensão, as práticas relativas à cura. A ausência de distinção nos termos da lei entre witch e witch doctor e a punição de pessoas que possuíssem objetos considerados "mágicos" se prestava a esta desarticulação do sistema mágico-religioso local.

As leis coloniais que criminalizavam a acusação de feitiçaria eram vistas pelos nativos como uma lei injusta ou mesmo como uma aliança com os feiticeiros, na medida em que o regime colonial reprimia justamente os considerados protetores da comunidade, os curandeiros, chefes e 
sacerdotes que acusavam os malfeitores místicos em prol do bem comum.

O Relatório propôs, em resumo, que se abandonasse o pressuposto colonial de que a feitiçaria seria abandonada à medida do "desenvolvimento civilizatório" e que se reconhecesse a feitiçaria como uma "realidade" africana, que exigiria soluções propriamente africanas. Ou seja, que o sistema judiciário reconhecesse a feitiçaria como crime, tal como é entendido popularmente. Sugeriu a produção de mecanismos legais para processar e julgar feiticeiros. O Estado, tomando em suas mãos as denúncias contra feiticeiros através de mecanismos legais para processá-los judicialmente, produziria a diminuição da descrença popular frente à lei, evitando os ataques mortíferos a feiticeiros e garantindo os direitos dos acusados. O relatório propôs assim, a substituição do "Witchcraft Supression Act" por um "Witchcraft Control Act".

Para que o sistema jurídico pudesse julgar adequadamente os supostos feiticeiros, emergiria como figura central no processo jurídico a figura do curandeiro tradicional, ou advinho (sangoma) como especialista capacitado para identificação de feiticeiros. Para atuar como auxiliares dos juízes e intermediários entre estes e população local, seria necessário, para este fim, o reconhecimento do curandeiro tradicional como uma figura distinta do feiticeiro ("corrigindo" a ambiguidade da legislação colonial que não distinguia witchdoctor e witch) e a regulação dos curandeiros tradicionais pelo Estado.

O Relatório aconselhou a forma jurídica praticada nos Camarões, onde os sacerdotes tradicionais (ngangas) são auxiliares dos juízes. Possuindo o "terceiro olho" são os únicos capazes de identificar corretamente os feiticeiros. Repõe-se, como no caso camaronês, o dilema da ausência da prova material, central no direito positivo que é substituído pelo aval qualificado do nganga (Fisiy e Geschiére 2001).

O debate gerado a partir da publicação do relatório foi repleto de críticas. A maior parte delas centrou-se na proposta do Estado reconhecer a feitiçaria, dando aval à ideia de que as acusações a feiticeiros teriam fundamento. Outras críticas centraram-se no questionamento da "africanização" do sistema jurídico e os riscos sobre as liberdades liberais e universais, a incompatibilidade entre os dois sistemas, a retomada do dualismo jurídico que marcou o sistema do indirect rule e do apartheid, o questionamento da concepção de feitiçaria como algo especificamente africano ${ }^{10}$. $\mathrm{O}$ exclusivismo racial presente nesta concepção foi um tema importante.

10 Para uma abordagem que, inversamente, procura pontos de aproximação entre o reconhecimento da feitiçaria e o liberalismo jurídico, Tebbe 2007. 
As leis "africanas" de combate à feitiçaria se aplicariam aos brancos e outros grupos minoritários dentro da África do Sul? As realidades "africanas" seriam racialmente ou culturalmente determinadas?

Outro ponto interessante do debate foi a tentativa de estabelecer uma linha demarcatória entre feiticeiros e curandeiros, quando do ponto de vista antropológico, esta distinção não é evidente, pondo ao encargo do Estado criar critérios que ele não seria capaz de produzir quanto a esta distinção (Niehaus 2001, Harnischfeger 2001) ${ }^{11}$.

\section{Indirect Rule e assimilacionismo português - combate à feitiçaria e razão de Estado}

As leis coloniais anti-feitiçaria no império britânico de certa forma estabeleceram um paradoxo com relação ao princípio geral do indirect rule (governo indireto) que tem por base o reconhecimento de dois sistemas legais regulados - o sistema civil, colonial, "branco", regrado por "leis universais", e o sistema colonizado, "nativo", regulado pelo sistema consuetudinário sob direção de chefes locais reconhecidos ou designados pela "administração" local. Havendo uma instância reconhecida de regulação de conflitos locais, através das chefias locais e dos tribunais "costumeiros" regidos por um suposto "direito consuetudinário", as leis anti-feitiçaria seriam uma das raras leis do sistema colonial a regularem diretamente conflitos locais. Ou seja, elas apareciam como uma intervenção excessiva das leis coloniais ("leis dos brancos") ao "costume”.

As leis anti-feitiçaria eram muito variáveis no espaço colonial britânico quanto ao seu detalhamento (podiam ser punidos não apenas os acusadores, mas também pessoas que se faziam passar por feiticeiros, pessoas que alegam o poder de enfeitiçar etc.), à severidade das penas bem como ao valor das multas e o tempo das detenções - quando havia. Eram mais duras na Rodésia, por exemplo, punindo não apenas o acusador, mas o witch doctor, quem foi à cerimônia do ordálio, etc. Em Gana, por outro lado, uma pequena multa punia apenas o acusador (Browne, 1935).

Por sinal, na década de 1930 instaurou-se um debate aceso entre administradores, antropólogos, juristas e outros profissionais sobre a pertinência e eficácia destas leis nos domínios britânicos. O número 8 da revista Africa de 1935, foi totalmente dedicada ao tema da feitiçaria. Organizada pelo antropólogo Evans-Pritchard, contém análises e etnografias antropológicas sobre

11 Em 2004 na África do Sul foi aprovado o "Traditional Health Practitioners Act”, visando, pela primeira vez, licenciar e regular a prática dos curandeiros (Tebbe 2007). 
as várias cosmologias e práticas concernentes à feitiçaria em diferentes espaços africanos, além de artigos de juristas, militares e administradores questionando a consistência, a eficácia e o significado para as populações nativas das leis anti-feitiçaria. Boa parte dos articulistas relatava a sensação de incompreensão das populações quanto à justiça da lei, se sentindo desprotegidas frente aos feiticeiros que, segundo estas populações, se tornavam ainda mais impunes.

Do ponto de vista da "missão civilizatória britânica", a crença na feitiçaria e os julgamentos aos feiticeiros pelo ordálio estavam na base do que deveria ser extirpado do continente africano, tal como a "escravidão", as guerras inter-tribais e o sacrifício humano (Lorde Lugard, apud Fields 1982). Entretanto, a par da boa consciência civilizadora, pode se pensar, de acordo com Fields, que o que estava na base do paradoxo acima referido, da proibição das acusações de feitiçaria no contexto do indirect rule, era o próprio risco da imposição da pena capital pelo tribunal costumeiro ao suposto feiticeiro ${ }^{12}$. Isso, do ponto de vista de implantação da ordem colonial significava um desafio à soberania do Estado, a quem cabe o monopólio legítimo da violência, ou, em última instância, embora não acionado com frequência no estado colonial, o direito de matar (Fields 1982, 576-77).

Sendo assim, as leis anti-feitiçaria relacionam-se não apenas com a imposição de uma "ideologia" civilizatória baseada no cristianismo, no direito natural ou nas concepções do direito positivo, mas sobretudo com a imposição da ordem colonial e da soberania do Estado colonial. Todavia, é também devido à necessidade de impor a ordem - e principalmente de mantê-la - que percebe-se uma enorme flexibilidade na aplicação da lei a nível local. O custo de impor leis à revelia, o risco de convulsões sociais ou crescimento do medo e ansiedade coletivas atribuído ao aumento da feitiçaria, as limitações do aparato repressivo em fazer valer a lei em todo o território, bem como o cálculo de não intervir mais que o necessário nas formas de resolução local foram fatores importantes que explicam as práticas de "vista grossa" em diversas situações de resoluções de conflito que envolveram a feitiçaria no contexto colonial, tal como apontado no contexto das colônias britânicas (Harnischfeger 2001).

O sistema colonial português, mesmo tendo por característica uma concepção assimilacionista e de centralização administrativa, manteve o enquadramento dos poderes locais, reconhecendo e nomeando chefes locais (chamados sobas ou régulos) necessários como correia de

12 A pena ao feiticeiro podia variar dependendo do mal causado: uma multa, a expulsão da aldeia, sua venda como escravo ou o sacrifício. 
transmissão da autoridade colonial. A estes eram atribuídos múltiplas obrigações como recolher impostos, recrutar trabalhadores, manter a ordem. Dentro desta última atribuição estava explicitamente a tarefa de "opor-se à prática de bruxarias e adivinhos e muito especialmente das que representam violência contra as pessoas" (Decreto lei 23.229 de 1933, apud. Conceição Neto 2004). Entretanto, não promoveu qualquer lei específica de supressão ou regulação da feitiçaria ou de acusação de feitiçaria. A subordinação do chefe local ao chefe de posto ou outras autoridades administrativas garantia a subordinação da instância local ao sistema geral. A legitimidade das chefias locais frente as populações garantia o funcionamento da ordem colonial ${ }^{13}$.

Não conseguimos obter dados suficientes para avaliar como na prática os conflitos relativos à acusação de feitiçaria eram resolvidos a nível local no período colonial, em Angola especificamente. Faltam dados primários que nos permitam avaliar como intervinham atores importantes, como chefes de posto, régulos e chefes tradicionais ou curandeiros em situações concretas de conflitos envolvendo feitiçaria. Entretanto algumas fontes missionárias permitem entrever como eram resolvidos certos conflitos a partir da atuação de missionários como mediadores, tanto de conflitos locais, como de questões que envolviam a população nativa e a administração colonial.

No caso do norte de Angola interessa perceber o papel das diferentes igrejas cristãs, pois a consolidação do poder português na região foi fortemente dependente da implantação da missão católica em 1881 e da habilidade política do padre Antônio Barroso que lá permaneceu durante 10 anos. Numa região disputada por várias potências coloniais, o missionário teve que equilibrar a influência da chamada Missão Inglesa (igreja batista) para garantir a influência portuguesa na região. São vários os relatos da solicitação da mediação do religioso em querelas internas aos poderes locais e envolvendo populações e autoridades coloniais (Brásio 1954). As mediações realizadas por religiosos são relatadas tanto por missionários católicos (Brásio 1954) como também batistas (Grenfel 1998) desde o começo do século. A disputa dos agentes religiosos nestes conflitos dá conta da sua atuação de formas distintas e assumindo uma variedade de papéis (Vos 2005) como parte interessada na relação entre locais e administradores.

Não é tarefa simples comparar sistemas coloniais quanto o britânico e o português, e em contextos distintos, sobretudo com a ausência de fontes primárias e dados secundários finos para $\mathrm{o}$

13 A manutenção deste sistema hierárquico e de duplicidade jurídica (sistema civil e sistema nativo) pode ser considerada também um sistema de indirect rule, como propõe Florêncio (2008). 
caso português em Angola. Entretanto, tomando também como base as pesquisas em Moçambique (Florêncio 2008, Granjo 2011), e considerando as reflexões em torno do pluralismo jurídico em África, estas caminham no sentido de relativizar a suposta rigidez do regime costumeiro bem como os limites na capacidade de repressão e imposição do regime colonial. Assim é plausível a hipótese de que as práticas locais eram variadas tanto no contexto britânico como português, muitas vezes convergindo para mesmo tipo de soluções. Ou seja, a adoção de soluções locais que apontam para a mediação local de conflitos sem a obediência restrita às legislações coloniais anti-feitiçaria e acompanhando o jogo de forças locais. No centro de Moçambique, entre os Ndau, Florêncio chama atenção, por exemplo, para as situações de manipulação pelas autoridades tradicionais quanto a não reportar crimes graves que deveriam ser solucionados pela administração (2008:276). Da mesma forma, em Angola, o mesmo autor também afirma que o mesmo acontece na região do Bailundo, em Angola (2011).

No contexto britânico, as leis de supressão da feitiçaria foram levadas localmente com algum pragmatismo. Neste caso, era evidente para os administradores locais que a manutenção da ordem em muitas situações estava acima de políticas coloniais impostas de cima, havendo um certo “deixa andar" em algumas situações de acusação menos graves, adotando-se uma política de "vista grossa" em casos de conflitos cuja intervenção colonial poderia implicar em maior convulsão social, deslegitimando para além do tolerável a chefia local. Variáveis como a força relativa de cada ator local: polícia, missionários, chefes de posto, chefes locais, a importância e o tamanho das famílias implicadas por parte dos acusadores e dos acusados, a posição social destes ou a gravidade da acusação faziam parte do cálculo destes administradores para que a resolução do problema permanecesse ocultado ou resolvido a nível familiar ou local.

No caso da colônia de Angola, especialmente na área norte (de população Bakongo) as regulações de conflitos locais que exigem a intervenção colonial eram extremamente limitadas pela maior fragilidade do estado colonial português nesta região, e mais ainda pela facilidade de trânsito na fronteira norte para a colônia do Congo Belga, muito acionada como válvula de escape para situações de conflitos mais graves ou de exploração mais flagrante, mesmo antes da eclosão da guerra colonial.

Em algumas entrevistas com religiosos que aturam no norte de Angola busquei informações de como são encaminhadas as acusações de feitiçaria na área rural das províncias em Angola e no meio urbano de Luanda. Famílias mais poderosas são capazes de impor ou ocultar julgamentos de 
feitiçaria à margem do controle do Estado ou com a conivência deste. Casos com pouca violência, por exemplo, costumam ser mais tolerados.

Em resumo, procurei apontar para dois aspectos presentes na implantação do estado colonial que parecem fazer sentido no período pós-colonial no que diz respeito à relação do Estado com as conturbações sociais relacionadas à feitiçaria. A primeira delas é que, mais do que o ímpeto civilizatório, a regulação da feitiçaria pelo Estado colonial estava baseada na disputa de poder no julgamento de crimes, em suma, na tentativa de monopolizar do uso da força pelo Estado. Segundo, e contrabalançando o primeiro aspecto, tanto as necessidades práticas de manutenção da ordem social como a fragilidade do Estado colonial em conter convulsões sociais e iniciativas locais de resolução de conflitos podem ter sido responsáveis pelo afrouxamento da repressão às acusações de feitiçaria.

\section{Comparando}

Uma comparação entre os casos contemporâneos angolanos e sul-africanos aqui apresentados permite estabelecer um breve quadro de semelhanças e diferenças nos aspectos dos eventos de acusação a ataques a feiticeiros, nas reações dos governos quanto a estes fatos e os processos de produção dos referidos relatórios.

Embora na bibliografia estudada não apareça com clareza o porquê dos casos de acusação e perseguição serem específicos da Nothern Province na África do Sul, no caso angolano, as acusações a crianças e adolescentes (que foram os casos que obrigaram o governo angolano a tomar posição) são um fenômeno basicamente concentrado na população Bakongo ${ }^{14}$. Outro elemento comum é a disseminação das igrejas evangélicas e africanas, que vem acirrando a violência das acusações através da formulação dos discursos anti-feitiçaria que instauram uma dualidade cosmológica mais marcada, que vem reduzindo as ambigüidades típicas dos discursos e práticas anteriores sobre feitiçaria (Niehaus 2001).

O envolvimento de jovens e crianças em acusações de feitiçaria é outra novidade, embora a posição dos jovens seja o oposto em cada situação: na África do Sul os jovens são os perpetradores das acusaçãos e em Angola, entre os Bakongo, e de forma bem incomum, as vítimas. Ainda assim, a

14 Os motivos pelos quais as acusações a crianças ser um fenômeno concentrado entre os Bakongo e não tão frequentes no resto do país não parecem ser conclusivas. Procurei apresentar algumas hipóteses em Pereira 2008. 
atribuição de poder aos jovens e crianças - seja um poder místico, no caso angolano, ou pela tomada de iniciativa político-religiosa, no caso sul-africano - é significativo na mudança da balança de poder entre gerações e dos novos papéis assumidos por crianças e adolescentes na África contemporânea (De Boeck e Honwana 2000, 2005).

Do ponto de vista do Estado, os casos havidos na África do Sul provocaram um desafio ao poder constituído pela perpetração de "justiça pelas próprias mãos". No caso angolano, o número significativo de crianças de rua indicam acusações de feitiçaria que se iniciam na esfera privada da família. O Estado angolano vem tentando reprimir e controlar, sobretudo, o papel das igrejas pentecostais, entendidas como principais fomentadoras das acusações a crianças. É fundamental compreender que o controle da chamada proliferação religiosa passa pelo controle de migração entre Congo e Angola, pois são atribuídos aos pastores de origem congolesa o foco dos distúrbios pela pregação anti-feitiçaria. A culpabilização dos pastores congoleses está na base de várias das ações e discursos de agentes do estado angolano sobre as acusações de feitiçaria ${ }^{15}$.

A comparação das diferentes formas de produção, circulação e recepção dos dois relatórios revela alguns aspectos. O Relatório Ralushai foi solicitado pelo governo e produzido por uma equipe multidisciplinar que envolvia técnicos sul-africanos e autoridades tradicionais. Esta variedade de origens dos autores do relatório pôde demonstrar vários pontos de vista sobre a questão. Foi publicado e largamente discutido (e polemizado). O relatório angolano foi solicitado pelo governo em colaboração com organismos internacionais e organizações não-governamentais e coordenado por uma antropóloga estrangeira, um sociólogo angolano com equipe local nãoespecializada. Reprovado pelos solicitantes, no bojo de desentendimentos de várias ordens, não chegou a ser publicado, nem seus resultados efetivamente debatidos com o argumento explícito de que apoiariam a idéia de que a criança era efetivamente feiticeira.

Os dois relatórios - Ralushai e Friedman-Nsenga - chamam atenção para a "realidade" da feitiçaria pela persistência de sua crença - recusando a perspectiva ocidental de, à partida, recusar a existência da feitiçaria. Se o relatório angolano apresentava uma perspectiva mais "cientificista", procurando as causas de tal persistência em fatores como pobreza, subdesenvolvimento e

15 Não só do Estado angolano. Um espaço importante para a observar as percepções dos angolanos tem sido os fóruns de discussão na internet e os comentários nos jornais on line. Embora restrita a uma pequena camada que tem acesso à internet, cuja boa parte está fora do país, a observação dos comentários sobre notícias relacionadas à feitiçaria são relativamente muito numerosas e repletas de comentários negativos aos Bakongo, às igrejas pentecostais e africanas e ao suposto "atraso africano" pela continuidade da crença na feitiçaria. Sobre rumor, internet e constução da nação, ver Trajano 2001. 
desestruturação social, em nenhum momento apontou para a necessidade de dirimir a crença na feitiçaria das populações implicadas. Todavia, alguns dos colaboradores da pesquisa angolana acreditavam efetivamente na feitiçaria e incorporaram estas convicções nos relatos de pesquisa e supostamente por isto saíram do projeto. No caso do Relatório Ralushai, havia um sangoma e um chefe tradicional ativamente envolvidos na sua produção e defensores explícitos da realidade e efetividade da feitiçaria.

Quanto à valorização de "autoridades tradicionais" e formas locais ou "tradicionais" de resolução e regulação de conflito há algumas distinções importantes entre os dois relatórios. No sulafricano, o curandeiro tradicional é a peça fundamental, o avalista do processo jurídico que se pretende instaurar contra acusados de feitiçaria. No relatório angolano ele é posto no mesmo lugar negativo - do pastor pentecostal. Para os autores do relatório angolano, as "autoridades tradicionais" são a únicas instâncias a serem acionadas na resolução do conflito, mas não se discute ali como seriam encarados os recursos místicos necessários para o julgamento da pertinência da acusação. Entendendo a feitiçaria apenas como uma crise no sistema social e de parentesco bakongo, os aspectos místicos e religiosos envolvidos nas concepções locais são relegados a um segundo plano no relatório não publicado. Esta percepção é evidente no relatório Friedman-Nsenga pela secundarização do personagem do adivinho ou curandeiro que não é considerado como peça importante nos julgamentos tradicionais.

\section{Conclusão}

A pergunta que moveu este texto - por que o relatório angolano não foi aprovado e o que isso revela do Estado angolano na sua relação com "realidades africanas" e conflitos não passíveis de serem abrigados pelo direito universalizante - abre várias pistas que aqui só será possível indicalas. A primeira delas remete à dificuldade do Estado angolano de lidar com questões como descentralização e valorização de discursos culturalistas de autenticidade e politização da africanidade. Esta dificuldade tem raízes na recente guerra civil, que opôs o partido no poder, MPLA, e a UNITA. A guerra civil (e antes dela, a guerra de libertação) alocou os dois partidos numa polaridade ideológica na qual o MPLA se encontrava no pólo "modernizante", urbano e pluriracial e a UNITA explorou até onde pôde discursos de autenticidade e resgate da "Angola profunda" de base rural anti-aculturativas. Não raro o líder da UNITA, Jonas Savimbi, se utilizou da acusação 
de feitiçaria para expurgar e assassinar dissidentes e controlar populações pelo terror ${ }^{16}$. Assim, a crescente ênfase na valorização da "africanidade" encontrada em discursos oficiais na África do Sul pós apartheid, como o reconhecimento da feitiçaria como realidade "africana", é bastante difícil de ser verificada entre elites angolanas ligadas ao partido no poder.

O governo angolano tem sido inconsistente na discussão sobre o lugar político, administrativo e simbólico das autoridades tradicionais. O reconhecimento da incontestável legitimidade que os chefes tradicionais exercem sobre as populações rurais e a necessidade de contar com estas autoridades para governar vem exigindo entretanto que o governo do pós-guerra ensaie algumas formas de delegação de poderes administrativos e políticos num Estado que permanece altamente centralizado (Orre 2008).

No começo de 2002 foi realizado pelo Ministério da Administração do Território o "I Encontro Nacional sobre Autoridade Tradicional em Angola" (houve um segundo, em 2006). Teve caráter mais "culturalista" do que realmente dedicado a pensar na possibilidade de combinar direito positivo e tradicional; mais de reconhecer notáveis locais do que discutir formas juridicamente válidas de regulações de conflitos locais. O caráter folclórico e culturalista vem se configurando numa "tradição" do Estado angolano de perceber a diversidade cultural e política do país. Esta postura sugere que as autoridades tradicionais vem merecendo mais um lugar como correia de transmissão na administração de Estado, de forma muito semelhante ao período colonial (Florêncio, 2011: 108) do que como um locus de produção de poder local com certa autonomia, traduzindo um pluralismo jurídico mais efetivo.

Cabe evidentemente apontar para os paradoxos da construção deste duplo sistema universalista e local ou "tradicional" - no que tange as contradições inerentes entre o sistema moderno e universalista, fundados na visão liberal e universalista do direito, e o sistema hierarquizado e gerontocrático do "poder tradicional", que entra frequentemente em choque com direitos humanos e democracia, fundados na noção de indivíduo. Sobre estas incompatibilidades e contradições às tentativas de regulação do poder tradicional nos modernos estados africanos, alguns autores têm sido referência para os casos moçambicano e angolano. Florêncio (2008) propõe a noção de neo indirect rule para análisar as continuidades das práticas coloniais e pós-coloniais quanto ao aproveitamento das autoridades tradicionais pelos Estados pós-coloniais. Orre (2008) se

16 Todavia ver Brinkman 2003 para os casos de punição por feitiçaria e traição envolvendo o MPLA na Frente Leste, durante a guerra anti-colonial. 
dedica a análise sobre instrumentalização partidária das autoridades tradicionais pelo Estado angolano (comparado ao moçambicano) no pós-guerra.

Ainda pode-se assinalar que, se as autoridades tradicionais estão integradas no Estado angolano sobretudo no aspecto intrumental da administração (Orre 2008), este mesmo Estado restringe autoritariamente os espaços nos quais as autoridades tradicionais podem atuar. Assim, as tentativas de pensar a ação das autoridades tradicionais em dimensões jurídicas e políticas não previstas pelo Estado, como julgamentos de crimes tal como estes são entendidos localmente, nem sequer é posta em debate. A evidência desta posição está na recusa do Relatório Friedman-Nsenga, que não sugere outra solução que respeitar e reforçar formas locais de resolução de conflito baseados na autoridade dos "mais velhos" e chefias locais.

Não encontrando qualquer forma reconhecer a "realidade da feitiçaria" como constitutiva de um universo social a ser levado em algum nível de consideração, resta ao Estado angolano não tomar conhecimento nos casos que são resolvidos a nível local ou, quando o fenômeno ganha uma visibilidade impossível de ignorar, como no caso das crianças acusadas de feitçaria, atribuí-lo ou à pobreza e subdesenvolvimento, retomando os mesmos argumentos de ordem pragmática e modernizante, ou dirigir às igrejas pentecostais e africanas, especialmente as vindas do Congo, a responsabilidade pela deturpação de práticas culturais supostamente harmônicas e não ameaçadoras da ordem até a disseminação pentecostal.

\section{Referências Bibliográficas:}

ASHFORTH, Adam, 1998, Witchcraft, Violence, and Democracy in the New South Africa. Cahiers d'études africaines, Volume 38, N. 150. p. 505 - 532

BAYART, Jean-François, 1993, The State in Africa: the politics of the belly. Londres: Longman.

BRINKMAN, Inge, 2003, "War, witches and traitors: cases from the MPLA's Eastern front in Angola (1966-1975)". The Journal of African History, v.44 i.2 p. 303-323.

BROWNE, Major G. St. Orde, 1935, "Witchcraft and British Colonial Law. Africa, n. 8, 481-487. 
CCF/Christian Children Fund, 2003, "Diagnóstico realizado no município de Mbanza Congo". Luanda.

CIEKAWY, Diane, 1998, "Witchcraft in Statecraft: Five technologies of power in Colonial and Postcolonial Kenya". African Studies Review, vol. 41, n 3:119-141.

CIEKAWY, Diane e GESCHIERE, Peter, 1998, "Containing Witchcraft: Conflicting Scenarios in Postcolonial Africa”. African Studies Review, vol 41, n 3: 1-14

COMAROFF, Jean e COMAROFF, John (orgs.), 1993, Modernity and its Malcontents: Ritual and Power in Postcolonial Africa. Chicago: University of Chicago Press.

, 1999, "Occult economies and the violence of abstraction: notes from the South African postcolony". American Ethnologist 26, n.2: 279-303.

DE BOECK, Filip, 2000, “Le 'Deuxième Monde' et les 'Enfants-sorciers"”. Politique Africaine. Le Dossier Enfants, jeunes et politique, $n^{\circ}$ 80: 32-57.

. 2004, "On Being Shege in Kinshasa: Children, the Occult, and the Street". In: F. De Boeck, M.F. Plissart. Kinshasa: Tales of the Invisible City. Ghent/ Tervuren: Ludion/Royal Museum of Central Africa.

. 2005, "The divine seed: Children, gift and witchcraft in Democratic Republic of Congo". In: F de Boeck, A. Honwana (eds.), Makers \& Breakers: Children \& Youth in Postcolonial Africa. Oxford: James Currey.

DE BOECK, F. \& HONWANA, A., 2000, "Faire et défaire la société: enfants, jeunes et politique en Afrique: introduction au thême". Politique Africaine. Le Dossier Enfants, jeunes et politique, $n^{\circ} 80: 5-11$.

, 2005, "Introduction: Children \& Youth in Africa : Agency, Identity and Place”. In: F de Boeck, A. Honwana (eds.), Makers \& Breakers: Children \& Youth in Postcolonial Africa. Oxford: James Currey.

DOUGLAS, Mary, 1970, "Introduction: Thirty years after Witchcraft, Oracles and Magic". In: M. Douglas.(ed.). Witchcraft, confessions and accusations. Londres: Tavistock.

FIELDS, Karen E., 1982, "Political Contingencies of Witchcraft in Colonial Central Africa: Culture and the State in Marxist Theory". Canadian Journal of African Studies, Vol. 16, No. 3, pp. 567-593. 
FISIY, Cyprian e GESCHIERE, Peter, 2001, "Witchcraft, development and paranoia in Cameroon: interactions between popular, academic and state discourse". H. Moore e T. Sanders. (eds.). Magical Interpretations, Material Realities: Modernity, Witchcraft and the occult in Postcolonial Africa. Londres: Routledge.

FLORÊNCIO, Fernando, 2011, "Pluralismo Jurídico e Estado Local em Angola: um olhar crítico a partir do estudo de caso do Bailundo". Antropologia Portuguesa, no 28, pps. 95-134.

FLORÊNCIO, Fernando, 2008, "Autoridades tradicionais vaNdau de Moçambique: o regresso do indirect rule ou uma espécie de neo-indirect rule?” Análise Social, vol. XLIII (2. ${ }^{\circ}$, 369391.

FRIEDMAN, Kajsa Ekholm e N’SENGA, Biluka Nsakala, 2002, Estudo sobre as crianças em situação de risco nas províncias de Zaire, Uige e Luanda. Relatório Preliminar. Luanda.

GESCHIERE, Peter, 1997. The Modernity of Witchcraft: politics and the occult in postcolonial Africa. Virginia: University Press of Virginia.

GRANJO, Paulo, 2011. Julgamentos de feitiçaria, hegemonias locais e relativismos. Publicado em http://www.buala.org/pt/a-ler/julgamentos-de-feiticaria-hegemonias-locais-erelativismos

GRENFELL, F. James, 1998, História da Igreja Batista em Angola (1879-1975). BMS.

HARNISCHFEGER. Johannes, 2001, "Witchcraft and the State in South Africa”. African Legal Studies. Vol 2. University of the North Press (Africa do Sul),78-115.

MELLAND, Frank, 1935, "Ethical and Political Aspects of African Witcheraft. Africa, n. 8, p. 495-503.

MENESES, M. Paula G., 2009. “Poderes, direitos e cidadania: O 'retorno' das autoridades tradicionais em Moçambique" Revista Crítica de Ciências Sociais, 87, Dezembro 2009: 9-42

MESAKI Simeon, 2009. "Witchcraft and the law in Tanzania". International Journal of Sociology and Anthropology Vol. 1(8) pp. 132-138, December, 2009

MOLINA, Javier Aguilar, 2005, The Invention of Child Withes in Democratic Republic of Congo: social cleansing, religious commerce and the difficulties of being a parent in a urban culture. Save The Children UK.

MOORE, Henrietta e SANDERS, Todd (eds.), 2001, Magical Interpretations, Material 
Realities: Modernity, Witchcraft and the occult in Postcolonial Africa. Londres: Routledge.

NETO, Maria da Conceição, 2004, "Respeitar o passado - e não regressar ao passado: contribuição ao debate sobre Autoridade Tradicional em Angola". lo Encontro Nacional sobre a Autoridade Tradicional em Angola. Ministério da Administração do Território. República de Angola.

NIEHAUS, Isak, 1998, “The ANC's Dilemma: The Symbolic Politics of Three Witch-Hunts in the South African Lowveld, 1990-1995". African Studies Review, vol. 41, n. 3: 93-118.

, 2001, Witchcraft, Power and Politics: exploring the occult in the South African lowveld. University of Michigan University Press.

ORRE, Aslak, 2008, "Fantoches e Cavalos de Tróia? Instrumentalização das autoridades tradicionais em Angola e Moçambique”. Cadernos de Estudos Africanos, n. 17/18. p. 139-178

PEREIRA, Luena, 2008, “Crianças Feiticeiras: reconfigurando família, igrejas e Estado no pós-guerra angolano". Religião \& Sociedade. v.28, p.30-55.

PEREZ Helena e BENGE, Casimira, 2006, O Impacto das Acusações de feitiçaria contra crianças em Angola: uma análise na perspectiva da proteção dos direitos humanos. Luanda: INAC/UNICEF.

ROBERTS, Clifton, 1935, "Witchcraft and colonial Legislation. Africa, n. 8, p. 488-494.

ROWLANDS, Michael, WARNIER, Jean-Pierre, 1988, "Sorcery, Power and the Modern State in Cameroon". Man, New Series, vol. 23, n. 1: 118-132.

SCHATZBERG, Michael G., 2000. "La sorcellerie comme mode de causalité politique". Politique Africaine. Le Dossier Povouirs Sorciers, n 79 : 33-47.

STOBART, E., 2006, Child Abuse Linked to Accusations of "Possession" and "Witchcraft". Research Report 750. Departament for Education and Skills. UK. http://www.dfes.gov.uk/research/data/uploadfiles/RR750.pdf.

STEWART, Pamela J. STRATHERN, Andrew.2004. Witchcraft, sorcery, rumors and gossip. Cambridge: Cambridge University Press.

TEBBE, Nelson, 2007, "Witchcraft and Statecraft: Liberal Democracy in Africa" The Georgetown Law Journal. Vol. 96. Pp.183-236.

TRAJANO FILHO, Wilson, 2001, "A nação na web: rumores de identidade na Guiné- 
Bissau." In. Peirano, Marisa (org). O dito e o feito: Ensaios de Antropologia dos Rituais. Rio de Janeiro, Relume Dumará. P. 85-112

UNICEF 2010. Children Accused of Witchcraft: An anthropological study of contemporary practices in Africa. Dakar.

VOS, Jelmer A., 2005, The Kingdom of Kongo and its borderlands: 1880-1915. Thesis Doctor of Philosophy in History. School of Oriental and African Studies. 